\title{
VIRTUELNO OKRUŽENJE ZA PRAKTIČNO UČENJE GRAFIČKOG DIZAJNA NA DALJINU
}

\author{
Zona Kostić ${ }^{1}$, Dragan Cvetković ${ }^{1}$, Aleksandar Jevremović ${ }^{1}$, \\ Duško Radaković ${ }^{2}$, Igor Franc ${ }^{1}$ \\ ${ }^{1}$ Singidunum University, Serbia \\ ${ }^{2}$ College of Professional Studies „Belgrade Politehnica“, Serbia
}

\begin{abstract}
:
Virtuelna realnost i "Web-bazirane" aplikacije pokazale su se kao dobra kombinacija za podršku obrazovanju i to, ne samo u smislu dostupnosti resursa učenja, nego i kao podrška kolaborativnom učenju. U ovom radu opisano je kako se navedene tehnologije koriste za učenje na daljinu, kroz praktičan rad i primenu. Predložena Web aplikacija omogućava izučavanje oblasti kroz interakciju korišćenjem virtuelnog interfejsa. Aplikacija predstavlja novi nastavni metod i u konkretnom radu primenjena je na prototip kursa za praktično učenje grafičkog dizajna sa predlogom za primenu i na drugim kursevima. Kreiranje virtuelne laboratorije zasniva se na korišćenju Web tehnologija virtuelne realnosti otvorenog koda. Prikazan metod omogućava 2D i 3D projektovanje u realnom vremenu, komunikaciju i kolaboraciju. Pored zaključaka izvedenih korišćenjem virtuelnih okruženja za "Web-bazirano" obrazovanje, date su predikcije po pitanju daljeg razvoja i budućeg korišćenja virtuelnih edukacionih sistema u praktičnom učenju i testiranju na daljinu.
\end{abstract}

\section{Key words:}

grafički dizajn, edukacioni sistem, virtuelna laboratorija, "Web-bazirana" kolaboracija, edukacija na daljinu.

Ovaj rad podržan je projektom Ministarstva za nauku i tehnološki razvoj (evidencioni broj III 44006).

\section{UVOD}

Tehnološke promene omogućavaju kreiranje novih aktivnosti i novonastale načine čine superiornim u odnosu na tradicionalne metode rada, stvarajući time dugotrajne inovacije u društvu. "Web-bazirano" obrazovanje je jedna od tih inovacija. Tehnologije virtuelizacije danas imaju veliki uticaj na edukaciju generalno. Ove promene se odražavaju, uglavnom, na proces izvođenja nastave, pomeranjem sa teorijskog izvođenja na praktično, prostorno i vremenski nezavisno. Interaktivne simulacije i virtuelna okruženja omogućavaju proces izučavanja kroz angažovanje i praktično saznanje. Studenti mogu da se kreću unutar 3D okruženja i stiču nova znanja, bilo u interakciji sa kolegama ili elementima okruženja. Dakle, virtuelno obrazovanje podrazumeva simulaciju realnih učionica i laboratorija, a pod terminom "realnih učionica" podrazumeva se interakcija između nastavnika i učenika na istom mestu i u isto vreme.

U okruženju on-line igara i virtuelnih svetova, milioni korisnika provode svoje (na specifičnom angažmanu ili slobodno) vreme u virtuelnim prostorima korišćenjem sopstvenih avatara (vizuelni pseudonim, odnosno digitalna reprezentacija korisnika). Ovaj vid interakcije je zastupljen u skoro svim aspektima života. Broj sati koji je dnevno utrošen na korišćenje kućnih konzola kojima se kontrolišu avatari je veći od vremena posvećenog filmovima i štampanim medijima zajedno.
Aktuelna tehnologija omogućava upotrebu i kreiranje sopstvenih virtuelnih prostora. Ovakav proces prate nove generacije učesnika [1] koje komuniciraju korišćenjem računarskih četova (eng. chat), socijalnih mreža i video igara. Pripadnici sa drugačijim stilovima učenja (eng. Learning Style) približavaju granice između realnog i virtuelnog. To ne podrazumeva nedostatak uočavanja razlike između ova dva sveta, već korišćenje oba istovremeno i podjednako dobro.

Danas studenti podižu nivo korišćenja tehnologija u obrazovanju, u poređenju sa prethodnim generacijama. Takvi i budući kreativci, koji su sposobni da kreiraju sopstveni sadržaj (sopstvenu realnost) žive u 3D svetu i očekuju da im aplikacije tokom školovanja i budućeg rada imaju 3D aspekte. Za njih su tastatura i miš kao ulazni uređaji danas prevaziđeni. Zbog toga je kompletan obrazovni proces diktiran promenama na polju softvera, hardvera, posebno u domenu prilagođavanja različitim korisnicima i upotrebom novih korisničkih interfejsa.

U ovom radu opisano je kako se "Web-bazirane" tehnologije koriste za kreiranje okruženja za učenje na daljinu, kroz praktičan rad i primenu. Predložena Web aplikacija omogućava izučavanje oblasti kroz interakciju korišćenjem različitih interfejsa, praktično testiranje primenom tutorijala i logičkih igara. Aplikacija predstavlja novi nastavni metod i u konkretnom radu primenjena je na prototip kursa za praktično učenje grafičkog dizajna sa predlogom za primenu i na drugim kursevima. Kreiranje 
virtuelne laboratorije zasniva se na korišćenju Web tehnologija virtuelne realnosti otvorenog koda. Prikazan metod omogućava $2 \mathrm{D}$ i $3 \mathrm{D}$ projektovanje u realnom vremenu, komunikaciju i kolaboraciju.

Nakon uvodnog dela u kojem je dato obrazloženje o potrebama istraživanja, $u$ narednim poglavljima rad obuhvata teorijska razmatranja, zatim se fokusira na funkcionalne zahteve, dizajniranje i implementaciju laboratorije, potom na procenu o primenjivosti i završava predikcijama o budućem razvoju i upotrebi rešenja.

\section{“WEB-BAZIRANA" VIRTUELNA REALNOST}

Polje virtuelne realnosti, multidisciplinarna oblast računarstva, nastalo je istraživanjem 3D interaktivnih grafika i simulacije vozila u periodu između 1960. i 1970. godine. Pojedini eksperimenti su pokazali da čovek može potpuno uroniti u okruženje uz pomoć kamere. Snaga ove tehnologije je pokazana na primeru [2] u kojem je opisano više oblika interaktivne grafike koja je kasnije postala popularna, uključujući proširenu (eng. Augmentated Reality) stvarnost, gde kompjuterski generisane slike postaju deo realnog okruženja, odnosno scena. Autor je koristio ovaj oblik virtuelne realnosti za praktičnu primenu u medicini uz upotrebu uređaja u obliku kacige za projektovanje okruženja. Kasnije je bio pogodan za razvijanje sličnih projekata u široj oblasti medicine, omogućavajući (tada, po prvi put) vizuelizaciju funkcija organa u ljudskom organizmu. Ideja je bila da se, ne samo vizuelizuju apstraktni pojmovi, već da se istim može pristupiti i na taj način (grafički) dalje vršiti njihovo istraživanje i ispitivanje [3].

\section{Tehnologije za 3D prikaz na Web-u}

Da bi se izgrađeni modeli iznova koristili i prenosili u formi već kreiranih okruženja ili virtuelnih svetova, izvedene su 3D grafičke aplikacije sa opcijama čuvanja elemenata, scena, animacija ili svetova. Međutim, taj segment je preobiman u spektru različitih tipova $3 \mathrm{D}$ grafičkih formata namenjenih radu sa Web aplikacijama. Pomenuto se odnosi na tehnologije za prikaz i razvoj interaktivnih 3D aplikacija, uglavnom bez softverskih dodataka. U najznačajnije (vodeće) standarde spadaju standardi Web3D konzorcijuma (VRML, X3D i X3DOM [4]) i WebGL [5]. Pomenute tehnologije dizajnirane su za kreiranje interaktivnih "Web-baziranih" 3D sadržaja pogodnih za integraciju sa multimedijom. Ipak, postoji značajna razlika između njih i njihova upotreba, uglavnom, zavisi od aplikacije za koju su namenjene.

Iz prethodno navedenih razloga nastaje X3DOM tehnologija koja objedinjuje sve kvalitete HTML5, CSS3, JS i WebGL standarda. X3DOM je okvir za integraciju i manipulaciju (X)3D scena sa HTML5 DOM elementima koja za prikaz koristi WebGL. Poseban softverski dodatak ili pregledač nije neophodan. Pomenute karakteristike uticale su na odabir X3DOM tehnologije za kreiranje virtuelnog okruženja opisanog u ovom radu.

\section{Pregled upotrebe okruženja virtuelne realnosti u edukaciji}

U ovom delu prikazan je pregled najznačajnijih rešenja iz oblasti kolaborativnog i konkurentog dizajniranja između udaljenih učesnika u procesu, kao i značaj i zastupljenost korišćenja tehnologija virtuelne realnosti u edukaciji. Virtuelna učionica sa pametnim tutorom je dobro rešenje, korisno za samostalnu organizaciju i učenje, ali bez ozbiljnijeg deljenja 3D modela među učesnicima [6]. Projekat pod imenom VIEW opisuje odličan kurs za studente inženjerstva, ali za individualno korišćenje bez kolaboracije sa drugim učesnicima [7]. Odličan i funkcionalan interfejs kreiran korišćenjem X3D tehnologije je, takođe, dobro rešenje, uz nedostatak mogućnosti za konkurentan rad [8].

Rešenje pod imenom EVE je po prirodi najbliže temi ovog rada [9]. Pod punim nazivom "EVE Training Area Tool" rešenje je realizovano korišćenjem EVE platforme [10]. Alat je prikazan u obliku 3D okruženja u kojem učesnici (prikazani u obliku avatara) sarađuju, komuniciraju $\mathrm{i}$ koriste različite alate $\mathrm{u}$ zajedničkom prostoru.

Uzimajući u obzir prethodno navedene nedostatke, u ovom radu autori su pokušali da pruže odgovore na probleme i objedine ih jednistvenim okruženjem. U narednom poglavlju biće opisana arhitektura sistema i kreiranje virtuelne laboratorije za kolaborativan i konkurentan praktičan rad na daljinu.

\section{ARHITEKTURA I INTERFEJS}

U ovom poglavlju opisana je arhitektura modela i njegovih komponenata koja se primenjuje za održavanje praktičnih vežbi na daljinu. Osnovu laboratorije čine virtuelne mašine različitih karakteristika i namene. Nakon njihove specifikacije sledeća važna komponenta je model 3D laboratorije koji predstavlja interfejs za on-line prisutne studente. Nakon razvoja modela laboratorije on se može primeniti na konkretnu infrastrukturu. Osnovne komponente infrastrukture čini virtualizacioni server (na kome se instanciraju virtuelne mašine laboratorije), tanki klijenti (putem kojih fizički prisutni studenti vrše interakciju), i Web server sa koga se spoljnim studentima isporučuju X3DOM model i VNC klijent.

\section{Kolaboracija i komunikacija}

Virtuelna laboratorija je deljeno virtuelno okruženje. Da bi se omogućio kolaborativan rad studenata, laboratorija se sastoji od alata i elemenata koji omogućavaju i doprinose ostvarenju realnih poteza u virtuelnom prostoru. Osnovni elementi su ekrani vidljivi i dostupni svim učesnicima u procesu dizajniranja. Učesnici u procesu su geografski udaljeni i njihovi ekrani sa aktivnim rešenjima dizajna su vidljivi svim kreatorima u procesu. Oni laboratoriji pristupaju preko Web-a (korišćenjem sopstvenih računara) i njihovi virtuelni ekrani postaju aktivni. Svaki od učesnika može pokrenuti i koristiti u istom trenutku više ekrana u laboratoriji (tehnički je izvodljivo), ali s obzirom na prirodu posla takva opcija nije bila neophodna. 


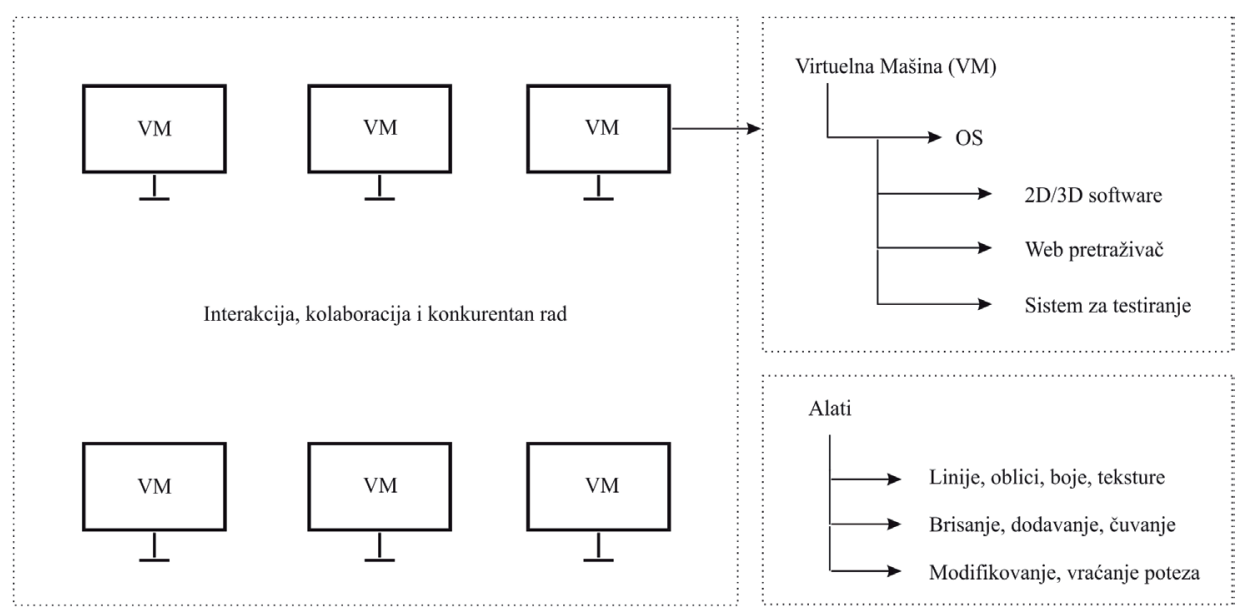

Slika 1: Interfejs za učenje grafičkog dizajna na daljinu

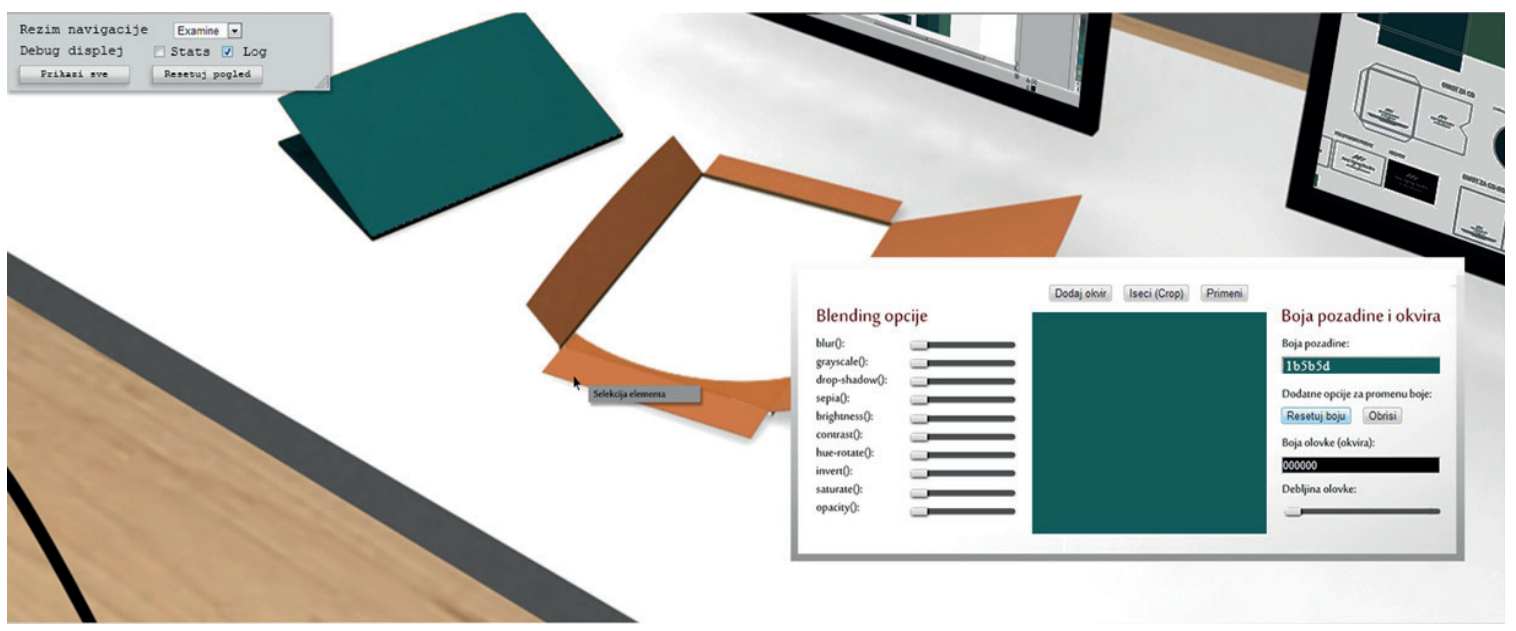

Slika 2: "Web-bazirani”" virtuelni interfejs

Za potrebe pristupa koriste se virtuelne mašine sa minimalnim setom softvera (samo softver za grafičku obradu) i Web pretraživačima odgovarajuće konfiguracije. $\mathrm{Na}$ taj način omogućena je integracija simulatora u 3D modelu korišćenjem VNC protokola i izbegnuta zavisnost od korisničkog Web pretraživača i njemu pridružene konfiguracije. Dodatno, na ovaj način omogućen je kolaborativni rad studenata, korišćenjem različitih programa, operativnih sistema, formiranjem uslova skoro jednakih uslovima fizičkog okruženja.

\section{Modelovanje "Web-bazirane" laboratorije}

Proces razvoja modela labortorije predstavlja složenu aktivnost u koju je uključeno više softverskih alata različitih namena. Pod razvojem modela laboratorije podrazumeva se razvoj modela 3D okruženja i pristup (iz laboratorije) virtuelnim mašinama koje će biti korišćene u laboratoriji. Blender je program za kreiranje i manipulaciju sa 3D grafikom [11]. Koristi se za modelovanje, kreiranje simulacija, animacija, vizuelnih efekata i $3 \mathrm{D}$ računarskih igara. Odabir ovog programa je usledio iz razloga što je reč o retkom softveru sa podrškom za izvoz X3D okruženja. Modelovanjem u Blenderu omogućena je lakša manipulacija, ažuriranje i korekcija. Ne samo da ima podršku za izvoz modela, već je i jedini koji ima mogućnost izvoza (X3D) animacija.

\section{"Web-bazirani" virtuelni korisnički interfejs}

Model "Web-bazirane" laboratorije prikazan na slici 2 kreiran je korišćenjem X3DOM tehnologije, odnosno upotrebom X3D tagova kao sastavih elemenata DOM strukture, čime se okruženje nesmetano izvršava u okviru Web pretraživača. Kolaborativno kreiranje korporativnog identiteta prikazano na slici detaljnije je opisano u narednom poglavlju.

\section{PRIMENA PREDLOŽENOG METODA I EVALUACIJA}

U ovom delu biće deljano opisan način izvođenja nastave kroz konkretan primer, odnosno korišćenje virtuelne laboratorije u cilju kreiranja zajedničkog brend identiteta. Oblast grafičkog dizajna je strogo praktičan rad i stoga ne postoji klasično izvođenje nastave u vidu teorijskog izlaganja, niti klasično testiranje. Takođe, istraživanjima iz stručne literature i testiranjem rešenja, zaključeno je da kolaborativan rad podstiče kompetitivnost i pojačava angažovanje. Posebno, u oblasti dizajna gde se iskustveno izučava, napredak individualnim radom nije srazmeran brzini razvoja iz konkretne oblasti.

Grupni rad podrazumeva praktičan rad u laboratoriji, koji uključuje šest članova: pet studenata osnovnih studija različitih godina studija i jednog master studenta kao 
vođe tima. Svaki od studenata, kao završni projekat na godini dostavlja svoj rad iz zajedničkog kreiranja brend identiteta.

Nakon definisanja koncepta instruktora, jedan student radi na kreiranju logotipa i vizuelnog koda, dok drugi radi na kreiranju elemenata vizuelnog identiteta. Prethodno pomenuti, dizajneri konceptualnog rešenja rade u kolaborativnom režimu gde njihov rad može i najčešće jeste praćen od strane ostalih kolega (koji ne mogu početi sa radom dok ova dva elementa ne budu završena). Ostali mogu, ne samo da prate, već i da modifikuju radove svojih kolega. Nekada u zavisnosti od težine projekta zadatak kreiranja logotipa može biti dodeljen svim članovima grupe, gde se na kraju od velikog broja rešenja bira jedno za dalji rad. Treći student na osnovu 2D rešenja kreira 3D elemente u namenskom programu za 3D modelovanje, četvrti na osnovu logotipa i koncepta kreira oglas (format i primena definisani su konceptom), dok peti radi na kreiranju izgleda Web stranice.

Laboratorija koja je definisana kao deljeni korisnički interfejs ima ugrađene sve alate za grafičko oblikovanje. Kreiranje elemenata vizuelnog identiteta radi se u programima za 3D modelovanje (virtuelne mašine), ali se gotovi elementi uvoze u zajedničko okruženje za dalje (zajedničko) modifikovanje (mapiranje, odnosno teksturiranje).

\section{Evaluacija}

Studenti grafičkog dizjana bolje razumeju proces, zadatke i brže dolaze do prvih idejnih rešenja kada je grupni rad zastupljen. Iako ne žele da pokažu svoja dizajnerska rešenja u početnim faza grupnog rada, studenti brzo shvate važnost zajedničkog rada u kasnijim iteracijama. Posebno se navedeno odnosi na studente koji se bave izradom grafičkog rešenja logotipa.

Problem predloženog rešenja modela virtuelne laboratorije je u brzini pristupa, iako je broj članova grupe relativno mali, kompleksnost okruženja uslovljen tipom predmeta koji se izučava, kao i veliki broj grupa obimno optrećuje sistem.

Kao najobjektivniju mogućnost za analizu efikasnosti virtuelne laboratorije u praktičnom korišćenju identifikovano je poređenje rezultata studenata koji su koristili fizičku računarsku laboratoriju i koji su koristili virtuelnu laboratoriju za kreiranje grupnih rešenja. Nepostojanje statistički značajne razlike između rezultata studenata iz fizičkog i virtualnog okruženja ukazuje na opravdanost koncepta i daljeg razvoja modela. Prevazilaženjem identifikovanih problema, uz korišćenje budućih, naprednijih verzija primenjenih tehnologija, može se očekivati izjednačavanje rezultata $i$, eventualno, postizanje statistički značajno boljih rezultata studenata koji koriste virtualna okruženja.

\section{ZAKLJUČAK I BUDUĆI RAD}

U ovom radu prikazan je jedinstven način izučavanja iz oblasti grafičkog dizajna na daljinu, a rešenje je primenjivo i na druge predmete izučavanja. Praktičan rad u predloženom rešenju može da se obavlja skoro bez ikakvih ograničenja i na način blizak realnim okruženjima. Predložena aplikacija predstavlja novi nastavni metod i u konkretnom radu primenjena je na prototip kursa za praktično učenje grafičkog dizajna. Kreiranje virtuelne laboratorije zasniva se na korišćenju Web tehnologija virtuelne realnosti otvorenog koda. Prikazan metod omogućava 2D i 3D projektovanje u realnom vremenu, komunikaciju i kolaboraciju.

Definisan koncept bi se mogao primeniti na druge kurseve. Kompletan predlog kurseva može se sumirati jedinstvenim virtuelnim edukacionim sistemom - materijali za učenje prilagođavaju se studentskim profilima, praktičan rad obavlja se u malim grupama. Budući razvoj interfejsa usmeren je na korišćenjes prirodnog korisničkog interfejsa (upotreba bez korišćenja miša i tastature).

\section{LITERATURA}

[1] K. Kapp, T. O'Driscoll, "Learning in 3D: Adding a New Dimension to Enterprise Learning and Collaboration", John Wiley \& Sons, 2010.

[2] I. Sutherland, "A Head-Mounted Three Dimensional Display," Proceedings of the Fall Joint Computer Conference, pp. 757-764, 1986.

[3] Greenfield, Harvey, D. Vickers, I. Sutherland, W. Kolff, "Moving Computer Graphic Images Seen from Inside the Vascular System", Transactions of the American Society of Artificial Internal Organs, pp. 381-385, 1971.

[4] X3DOM dokumentacija, izvor:

http://media.readthedocs.org/pdf/x3dom/latest/x3dom.pdf (pristup: 24.03.2014. god)

[5] S. Ortiz, "Is 3D Finally Ready for the Web?," Computer, pp. 14-16, 2010.

[6] Y. Hu, G. Zhao, "Virtual Classroom with Intelligent Virtual Tutor", Proceedings of the 2010 International Conference on e-Education, e-Business, e-Management and e-Learning - IC4E ‘10, 2010.

[7] P. Goeser, W. Johnson, F. Hamza-Lup, D. Schaefer, "VIEW: A Virtual Interactive Web-based Learning Environment for Engineering" IEEE Advances in Engineering Education Journal - Special Issue on Research on e-Learning in Engineering Education, pp. 1-24, 2011.

[8] L. Haiqing, Y. Guofu, F. Jie, "Research on the Collaborative Virtual Products Development Based on Web and X3D", International Conference on Artificial Reality and Telexistence, pp. 141-144, 2006.

[9] C. Bouras, C. Tegos, V. Triglianos, T. Tsiatsos, "X3D Multiuser Virtual Environment Platform for Collaborative Spatial Design", Proceedings of the 27th International Conference on Distributed Computing Systems Workshops - ICDCSW '07, 2007.

[10] Ch. Bouras, D. Psaltoulis , Ch. Psaroudis, Th. Tsiatsos, "Multi-User Layer in the EVE Distributed Virtual Reality Platform", International Conference on Distributed Computing Systems, pp. 602 - 607, 2003.

[11] Alat za 3D modelovanje "Blender", izvor: www.blender. org/ (pristup: 24.03.2014. god) 


\section{Abstract:}

Virtual reality and Web-based applications have been recognized as an important technological combination for supporting education, not only in the resource-based learning, but also in various collaborative e-learning processes. In this study, using mentioned technologies for distance learning with practical exercises, is presented. Proposed Web application allows learning and testing through interaction using virtual user interfaces. Application represents a new teaching facility and may serve as a prototype graphics design distance learning course with practical exercising implemented using this novel method. The laboratory enables real-time $2 \mathrm{D}$ and $3 \mathrm{D}$ design, communication, and group collaboration. Based on using applitaction, suggestions and predictions are given about future development and use of virtual educational systems in distance learning.

\section{Key words:}

graphics design, educational system, virtual laboratory, Web-based collaboration, distance education. 